\title{
IMPROVED AQUEOUS DISSOLUTION OF NIMODIPINE USING SELF-MICROEMULSIFYING SOLID COMPOSITIONS
}

\author{
YONG HAK LEE", DOHYUN KIM", BYOUNG HYEN KO, YOUNGWOO KIM, \\ MYA THET PAING SOE, YEE YEE TIN, and JAEHWI LEE*
}

College of Pharmacy, Chung-Ang University, Seoul, Republic of Korea

\begin{abstract}
Nimodipine is a highly lipophilic calcium channel blocker presenting extremely low aqueous solubility. This study aimed to develop solid self-microemulsifying tablets (SSMETs) that can considerably increase the apparent aqueous solubility and dissolution of nimodipine. For the selection of proper components of liquid state self-microemulsifying formulations (LSMEFs), nimodipine solubility and emulsification capability were evaluated. Based on these two factors, Capryol ${ }^{\mathrm{TM}}$ 90, Cremophor $^{\mathbb{B}}$ EL, and polyethylene glycol 400 (PEG 400) were chosen as oil, surfactant, and co-surfactant, respectively. The optimized LSMEF was then established through the construction of pseudo-ternary phase diagrams. Next, to solidify the optimized LSMEF, several adsorbents were screened, and the LSMEF solidified with Neusilin ${ }^{\circledR}$ UFL2 showed the highest dissolution profile with an appropriate solvent binding capacity. To further facilitate the drug release from the SSMETs, several disintegrants were investigated, and the SSMET containing Primellose ${ }^{\circledR}$ as a disintegrant substantially increased the dissolution of nimodipine. In addition, when the SSMET re-dispersed in simulated intestinal fluid, the SSMET successfully formed microdroplets presenting similar small size $(\sim 90 \mathrm{~nm})$ to droplets dispersed from the LSMEF. These results demonstrated that this SSMET we designed is a promising drug delivery system for poorly soluble drugs, such as nimodipine.
\end{abstract}

Keywords: self-microemulsifying tablet, solubility, adsorbent, microemulsion, self-microemulsifying drug delivery system

Approximately $40 \%$ of commercially available drugs and $90 \%$ of newly proposed drugs in the pipeline are poorly soluble (1). Drugs showing poor aqueous solubility and high permeability belong to class II of the biopharmaceutics classification system (BCS), and oral bioavailability of these drugs is largely governed by the aqueous solubility and dissolution $(2,3)$. Therefore, pharmaceutical scientists have strived for decades to improve the apparent solubility and dissolution of BCS class II drugs. In this regard, multiple strategies have been explored such as solid dispersions, nanoparticles, nanocrystals, and selfmicroemulsifying systems (4-10). Of them, the self-microemulsifying system, an isotropic and thermodynamically stable mixture composed of oil, surfactant, and co-surfactant, can be usefully exploited to increase the aqueous solubility and dissolution of poorly soluble drugs $(11,12)$. When orally administered, it can be spontaneously dispersed as oil droplets with sizes lower than
$100 \mathrm{~nm}$ by gentle agitation in the gastrointestinal tract. The resultant micro-sized oil droplets can provide a large surface area, leading to fast dissolution and absorption of the drug. Moreover, as the self-microemulsifying systems consist of lipophilic excipients, poorly-soluble lipophilic drugs can be efficiently incorporated into the systems, and also this lipophilic property of the self-microemulsifying systems can affect drug absorption by promoting intestinal lymphatic transport of the formulations (13).

Nimodipine, a dihydropyridine-type calcium channel blocker, acts as a vasodilator of cerebral blood vessels (14). As the self-microemulsifying system has advantages in improving the dissolution of highly lipophilic drugs, nimodipine is a good model drug for our study since it is a highly lipophilic drug ( $\log \mathrm{P}$ value of 3.05$)$ and belongs to BCS class II, showing extremely poor aqueous solubility $(2.30 \mu \mathrm{g} / \mathrm{mL})$ and high permeability $(15,16)$.

\footnotetext{
\# These authors contributed equally to this work

* Corresponding author: e-mail: jaehwi@cau.ac.kr
} 
The liquid state self-microemulsifying formulations (LSMEFs) have distinct advantages such as considerably rapid and spontaneous dispersion as drugs are solubilized in micro-sized droplets upon contact with the gastrointestinal fluid, leading to highly enhanced dissolution (12). However, as the self-microemulsifying systems are liquid form, several limitations remain including difficulty in handling, and low patient compliance (17-19). In previous studies, therefore, various strategies have been investigated to fabricate solid type dosage forms with LSMEFs, such as transferring the LSMEFs to soft gelatin capsules, solidification of the LSMEFs by adsorbents, and encapsulating the solidified-LSMEFs to hard gelatin capsules $(11,20$ 22). Among these, it seems that adsorbent-based solid formulation would be most convenient and efficient in developing solid dosage forms of LSMEFs based on our experience and literature survey (21, 23-25). However, in general, the dissolution of a drug incorporated into solidified-LSMEFs is not as efficient as LSMEFs. Therefore, in the current study, we attempted to develop solidified-LSMEFs that can demonstrate fast dissolution of nimodipine similar to that shown by LSMEFs.

Hence, the aim of this study was to design solid self-microemulsifying tablets of nimodipine (SSMETs) for enhanced aqueous solubility and dissolution of nimodipine as a BCS class II model drug. Indeed, this SSMET was expected to have inherent advantages of LSMEFs, demonstrating dissolution behaviors of nimodipine as fast as LMSEFs. Its behavior was assessed by droplet size measurement and in vitro dissolution test using simulated intestinal fluid (SIF).

\section{EXPERIMENTAL}

\section{Materials}

Nimodipine was purchased from Toronto Research Chemicals Inc. (Ontario, Canada). Labrafill $^{\circledR}$ M 1944 CS, Labrafac ${ }^{\circledR}$ Lipophile, Labrafac $^{\circledR}$ CC, Labrasol ${ }^{\circledR}$, Lauroglycol ${ }^{\circledR}$ FCC and Capryol $^{\text {TM }} 90$ were obtained from Gattefosse (Lyon, France). PEG 400 was purchased from Duksan Pure Chemicals (Ansan, Korea). Cremophor ${ }^{\circledR}$ EL was obtained from BASF (Ludwigshafen, Germany). Myvacet $^{\mathrm{TM}}$ 9-45 was kindly supplied by Richwood (Seoul, Korea). Aerosil ${ }^{\circledR} 200$ and Aeroperl ${ }^{\circledR}$ 300 pharma were purchased from Evonik Industries AG (Essen, Germany). Neusilin ${ }^{\circledR}$ UFL2 was obtained from Fuji Chemical Industry Co., Ltd (Toyama, Japan). Amberlite ${ }^{\circledR}$ IRP-88 was purchased from Rohm and Haas Co., Ltd (Philadelphia,
USA). Polyplasdone ${ }^{\mathrm{TM}}$ was obtained from Ashland (Wilmington, USA). Primellose ${ }^{\circledR}$ was obtained from DFE pharma (Hardenberg, Germany). Highperformance liquid chromatography (HPLC)-grade acetonitrile and ethanol were purchased from J. T. Baker (Phillipsburg, USA). Distilled and deionized water was used for the preparation of all solutions.

\section{Solubility test and HPLC assay}

An excessive amount of nimodipine ( $>2 \mathrm{~g})$ was added to $1 \mathrm{~mL}$ of each kind of oil, surfactant, and co-surfactant, and the mixtures were blended by stirring with a magnetic bar at a constant temperature of $25^{\circ} \mathrm{C}$ for 3 days until the mixture reached equilibrium. The equilibrated samples were centrifuged at $3000 \mathrm{~g}$ for $10 \mathrm{~min}$, after which the supernatant was collected and filtered through a $13 \mathrm{~mm}$ $0.45 \mu \mathrm{m}$ PVDF syringe filter. These filtrates were diluted with ethanol at a dilution ratio of 100 . The concentration of nimodipine was measured using HPLC (Waters, Milford, MA, USA). The HPLC system was composed of a binary HPLC pump (Waters 1525), an ultraviolet/visible detector (Waters 2489), and an autosampler (Waters 2707). The mobile phase was a mixture of acetonitrile and purified water $(70: 30, v / v)$. The sample was injected into a Luna C18 (2) $(4.6 \times 150 \mathrm{~mm}, 5 \mu \mathrm{m})$ column (Phenomenex, Torrance, CA, USA) maintained at $30^{\circ} \mathrm{C}$, at a flow rate of $1.0 \mathrm{~mL} / \mathrm{min}$, and detected at a wavelength of $235 \mathrm{~nm}$.

\section{Evaluation of emulsification capability}

The emulsification capability of various surfactants and co-surfactants to oil was assessed to find out proper combination based on the aqueous titration method (26). The mixtures of surfactants and co-surfactants at the ratio of $1: 1$ were added to the various weight fraction of oil, which was selected on the basis of the solubility test, after which the mixtures were blended with a magnetic stirring bar at $600 \mathrm{rpm}$ and $25^{\circ} \mathrm{C}$ until homogeneous. Later on, $0.2 \mathrm{~mL}$ of each blended mixture was diluted with $200 \mathrm{~mL}$ of water in a glass beaker, and then gently agitated with a magnetic stirrer at $100 \mathrm{rpm}$ and $25^{\circ} \mathrm{C}$. The resultant solutions were evaluated whether transparent microemulsion was formed by visual inspection for 1 day.

\section{Construction of pseudo-ternary phase diagrams}

Pseudo-ternary phase diagrams for various combinations of oil (Capryol ${ }^{\mathrm{TM}}$ 90), surfactants (Cremophor ${ }^{\circledR}$ EL), and co-surfactants (PEG 400) were constructed. The surfactant and the 
co-surfactant mixtures were prepared at varying weight ratios (1:1, 1:2, $1: 3)$, after which each mixture was blended with oil, at the various weight ratios, until homogeneous. The mixtures were then added to water and gently stirred at $25^{\circ} \mathrm{C}$ using a magnetic stirring bar. Three different pseudoternary phase diagrams were therefore established according to the different ratios of surfactant and co-surfactant, which were $1: 1,1: 2$, and $1: 3$. Each pseudo-ternary phase diagram was illustrated based on the evaluation of 36 combinations, which were prepared by blending the components (oil, water, and the mixture of surfactant and co-surfactant) with $10 \%$ differences. The blended samples were visually observed to confirm phase clarity. Through visual observation, we classified the categories as emulsion and microemulsion. When the samples showed a milky and cloudy appearance, we determined that the samples formed emulsion. Instead, microemulsion was indicated in the diagram when the blended samples appeared to be transparent and translucent.

\section{Preparation of LSMEFs}

Based on the solubility test and pseudo-ternary phase diagrams, Capryol ${ }^{\mathrm{TM}}$ 90, Cremophor $^{\circledR}$ EL, and PEG 400 were selected to fabricate the LSMEF. Capryol ${ }^{\mathrm{TM}}$ 90, Cremophor ${ }^{\circledR}$ EL, and PEG 400 were mixed at the ratio of $1: 1.5: 1.5(\mathrm{w} / \mathrm{w})$, and $30 \mathrm{mg}$ of nimodipine was added to $1 \mathrm{~mL}$ of the mixture. This mixture was then gently stirred at $100 \mathrm{rpm}$ and $25^{\circ} \mathrm{C}$ until all nimodipine was completely dissolved.

\section{Binding capacity test of the adsorbents for the solvents}

The binding capacity of the adsorbents for solvents was assessed by blending the adsorbents with solvents. Capryol ${ }^{\mathrm{TM}}$ 90, Cremophor ${ }^{\circledR}$ EL, PEG 400, and LSMEF were added to $1 \mathrm{~g}$ of adsorbents in a mortar, and the mixture was gently mixed for $5 \mathrm{~min}$ at $25^{\circ} \mathrm{C}$. The binding capacity of the adsorbents was determined as the highest amount of solvent in which the solidified formulation appeared as dry and free-flowing.

\section{Preparation of SSMETs}

The nimodipine-loaded LSMEF with the optimized composition was solidified with the adsorbents. The ratio of the nimodipine-loaded LSMEF and adsorbents was determined based on the result of the binding capacity of the adsorbents for the nimodipine-loaded LSMEF. The prepared LSMEF was blended with adsorbents with a specific ratio of $1 \mathrm{~mL}$ of LSMEF per $1.2 \mathrm{~g}$ of adsorbent (F2-F4), using mortar and pestle until the mixtures appeared to be freely flowable. For F5-F7, disintegrants were further added as $5 \%(\mathrm{w} / \mathrm{w})$ of the final SSMET formulation. F8 was a lab-scale control tablet containing Neusilin ${ }^{\circledR}$ UFL2, Primellose ${ }^{\circledR}$, and equivalent nimodipine raw powder instead of LSMEF. The resultant solidified mixtures were then passed through a sieve with a mesh size of $420 \mu \mathrm{m}$ before tablet compression. Finally, the sieved powder was compressed using the manual hydraulic press (Riken Power, Riken Seiki Co., Ltd., Japan) with flat-faced $13 \mathrm{~mm}$ punches, under the compaction force of $100 \mathrm{kgf} / \mathrm{cm}^{2}$. The compositions of the formulations were shown in Table 1.

\section{Evaluation of physical properties of the solidified-LSMEFs and SSMETs}

Regarding the physical property of the solidified-LSMEFs, a flowability test was performed. Bulk and tapped density of the solidified-LSMEF were measured by Jolting Volumeter (JV 1000, COPLEY, UK), and these data were used to evaluate the flowability of the powder by calculating

Table 1. Compositions of nimodipine-loaded LSMEF and SSMET formulations.

\begin{tabular}{|c|c|c|c|c|c|c|c|c|}
\hline Ingredients & F1 & F2 & F3 & F4 & F5 & F6 & F7 & F8 \\
\hline Nimodipine-loaded LSMEF* (mL) & 0.33 & 0.33 & 0.33 & 0.33 & 0.33 & 0.33 & 0.33 & \\
\hline Nimodipine powder (mg) & & & & & & & & 10 \\
\hline Aerosil $^{\circledR} 200(\mathrm{mg})$ & & 400 & & & & & & \\
\hline Aeroperl $^{\circledR} 300$ Pharma (mg) & & & 400 & & & & & \\
\hline Neusilin $^{\circledR}$ UFL2 (mg) & & & & 400 & 400 & 400 & 400 & 400 \\
\hline Amberlite $^{\circledR}$ IRP-88 (mg) & & & & & 40 & & & \\
\hline Primellose $^{\circledR}(\mathrm{mg})$ & & & & & & 40 & & 40 \\
\hline Polyplasdone $^{\mathrm{TM}}(\mathrm{mg})$ & & & & & & & 40 & \\
\hline
\end{tabular}

* Nimodipine-loaded LSMEF contains $30 \mathrm{mg} / \mathrm{mL}$ of nimodipine. LSMEF; liquid self-microemulsifying formulation. 
Table 2. Solubility of nimodipine measured in various oils and surfactants.

\begin{tabular}{|c|c|c|}
\hline Reagent & Classification & Solubility $(\mathrm{mg} / \mathrm{mL})$ \\
\hline Labrafac $^{\circledR}$ Lipophile & Oil & $8.17 \pm 0.14$ \\
\hline Labrafill $^{\circledR}$ M 1944 CS & Oil & $13.92 \pm 0.97$ \\
\hline Labrafac $^{\circledR}$ CC & Oil & $9.07 \pm 0.36$ \\
\hline Myvacet $^{\mathrm{TM}} 9-45$ & Oil & $9.64 \pm 0.57$ \\
\hline Capryol $^{\mathrm{TM}} 90$ & Oil & $25.15 \pm 0.70$ \\
\hline Cremophor $^{\circledR} \mathrm{EL}$ & Surfactant & $33.20 \pm 1.05$ \\
\hline Labrasol $^{\circledR}$ & Surfactant & $112.17 \pm 0.79$ \\
\hline Lauroglycol $^{\circledR} \mathrm{FCC}$ & Co-surfactant & $14.55 \pm 1.28$ \\
\hline PEG 400 & Co-surfactant & $88.47 \pm 8.70$ \\
\hline
\end{tabular}

The data are expressed as mean $\pm \mathrm{SD}, \mathrm{n}=3$. PEG, polyethylene glycol.

Hausner's ratio and compressibility index. In addition, as for the physical properties of the SSMETs, tablet weight, thickness, hardness, and disintegration time were evaluated. The hardness of the tablets was assessed by measuring the maximum tablet breaking force using a portable tablet hardness tester (EH-01, Electrolab, India), and a disintegration test was carried out using USP disintegration apparatus at $1 \mathrm{~L}$ of SIF and $37.0^{\circ} \mathrm{C}$.

\section{In vitro dissolution test}

Dissolution profiles were determined according to the United States Pharmacopeia (USP) dissolution apparatus II method. The LSMEF, SSMETs, and raw materials were added to SIF $(900 \mathrm{~mL}, \mathrm{pH}$ $6.8,37 \pm 0.5^{\circ} \mathrm{C}$ ) and agitated at a paddle speed of $75 \mathrm{rpm}$. Then, the samples $(2 \mathrm{~mL})$ were withdrawn at 5, 10, 20, 30, 60, 120, 180, and $240 \mathrm{~min}$. After sample collection, $2 \mathrm{~mL}$ of fresh dissolution media was replenished. All withdrawn samples were centrifuged at 12,800 rpm for $10 \mathrm{~min}$, after which the supernatants were filtered through a $0.45 \mu \mathrm{m}$ syringe filter. The levels of nimodipine were determined by HPLC, as described above.

\section{Measurement of emulsion droplet sizes}

Liquid or solid self-microemulsifying formulations were added to SIF $(900 \mathrm{~mL})$, followed by stirring for $4 \mathrm{~h}$ at a constant temperature of $37^{\circ} \mathrm{C}$. After $4 \mathrm{~h}$, the samples $(5 \mathrm{~mL})$, which contained oil droplets dispersed in SIF, were collected. The droplet size of the samples was determined using Zetasizer Nano ZS (Malvern Instrument, Worcestershire, UK).

\section{Statistical analysis}

All experiments were performed in triplicate and expressed as a mean \pm standard deviation
(SD), where appropriate. All data were collated and analyzed with Excel software. The student's $t$-test was conducted to analyze the data, and a $p$-value $<0.05$ was considered statistically significant.

\section{RESULTS}

\section{Solubility test}

To screen the suitable ingredients, we evaluated the solubility of nimodipine in multiple oils, surfactants, and co-surfactants as shown in Table 2. For oils, Labrafac ${ }^{\circledR}$ Lipophile, Labrafill $^{\circledR}$ M 1944 CS, Myvacet ${ }^{\text {TM }}$ 9-45, Labrafac ${ }^{\circledR}$ CC, and Capryol $^{\mathrm{TM}}$ 90, were tested, and of these, Capryol ${ }^{\mathrm{TM}}$ 90 demonstrated the highest solubility of nimodipine. As for surfactants, two surfactants were examined. Labrasol ${ }^{\circledR}$ presented higher solubility of nimodipine than Cremophor ${ }^{\circledR}$ EL. Regarding cosurfactants, Lauroglycol ${ }^{\circledR}$ FCC, and PEG 400 were tested. PEG 400 exhibited higher solubility than Lauroglycol ${ }^{\circledR}$ FCC.

\section{Evaluation of emulsification capability}

Capryol $^{\mathrm{TM}} 90$ was selected for the oil phase owing to its high solubility of nimodipine. However, unlike the oil, when screening the surfactants and co-surfactants, emulsification capability was mainly considered. We screened two different surfactants (i.e., Cremophor ${ }^{\circledR}$ EL and Labrasol $^{\circledR}$ ) and co-surfactants (i.e., Lauroglycol ${ }^{\circledR}$ FCC and PEG 400), respectively. Among the multiple combinations tested, the formulations composed of Capryol ${ }^{\mathrm{TM}}$ 90, Cremophor ${ }^{\circledR} \mathrm{EL}$, and PEG 400 could be quickly dispersed in water, and the resulting samples, dispersed in water, appeared to be transparent. 
A

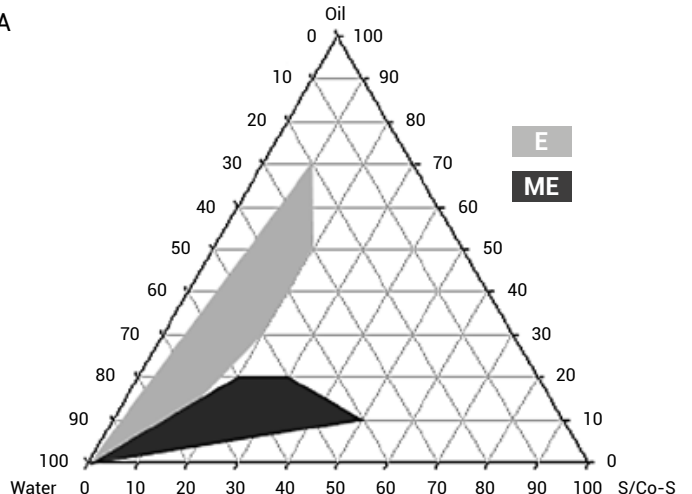

B

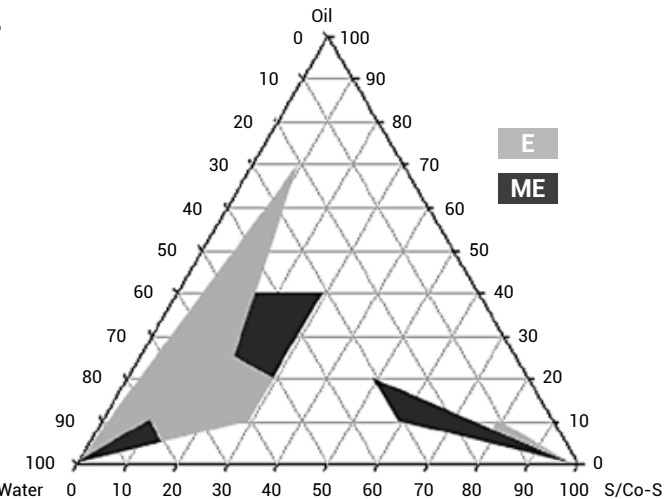

$\mathrm{C}$

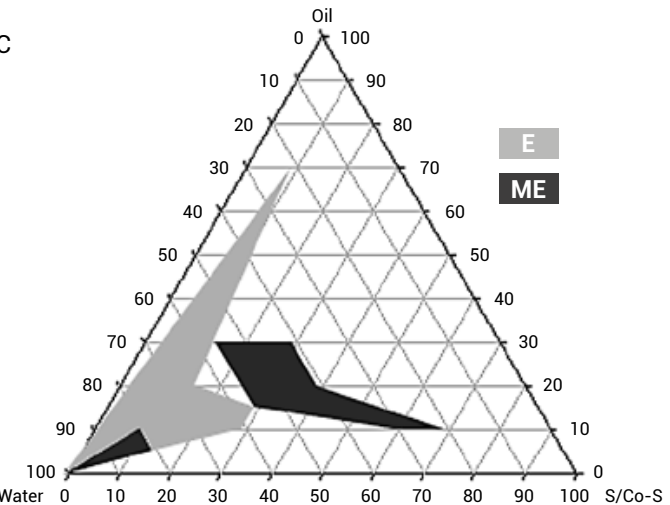

D

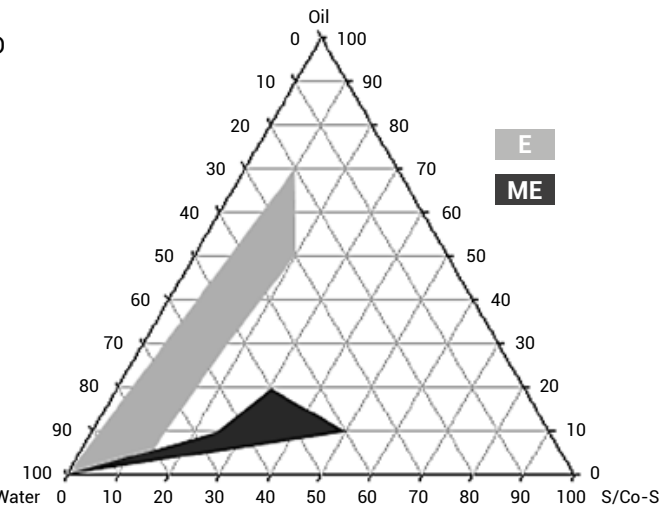

Figure 1. Pseudo-ternary phase diagrams of formulations consisting of Capryol ${ }^{\mathrm{TM}} 90$ as an oil, Cremophor ${ }^{\circledR}$ EL as a surfactant, PEG 400 as a co-surfactant, and water at ratios of (A) 1: 1, (B) 1:2, and (C) 1: 3 of Cremophor ${ }^{\circledR}$ EL and PEG 400. Panel (D) illustrates the diagram of a nimodipine-loaded formulation composed of nimodipine, Capryol ${ }^{\mathrm{TM}}$ 90, Cremophor ${ }^{\mathbb{B}}$ EL, and PEG 400 at a 1: 1 ratio of Cremophor ${ }^{\circledR}$ EL and PEG 400. S, surfactant; Co-S, co-surfactant; E, emulsion; ME, microemulsion.

\section{Construction of pseudo-ternary phase diagrams}

Pseudo-ternary phase diagrams were produced using Capryol ${ }^{\mathrm{TM}} 90$ and three different ratios of Cremophor $^{\circledR}$ EL and PEG 400 (surfactant and cosurfactant) as $1: 1,1: 2$, and $1: 3$ (Figure 1A-C). For the formulation of the self-microemulsifying system, the $1: 1$ ratio of the Cremophor ${ }^{\circledR}$ EL and PEG
400 formulations was chosen based on the size of the microemulsion area.

The pseudo-ternary phase diagram of nimodipine-loaded LSMEF is presented in Figure 1D. The microemulsion region in Figure 1D presented a slight change in the microemulsion area when compared with that of Figure 1A. Considering this change, the ratio of oil was selected in the range of $10-20 \%$,

Table 3. Solvent binding capacity of several adsorbents with different solvents.

\begin{tabular}{|c|c|c|c|}
\hline \multirow{2}{*}{ Solvent } & \multicolumn{3}{|c|}{ Solvent binding capacity (mL/g) } \\
\cline { 2 - 4 } & Aerosil $^{\circledR} 200$ & Aeroperl ${ }^{\circledR} 300$ Pharma & Neusilin $^{\circledR}$ UFL2 \\
\hline Capryol $^{\text {TM } 90}$ & $1.05 \pm 0.11$ & $1.30 \pm 0.11$ & $1.21 \pm 0.18$ \\
\hline Cremophor $^{\circledR}$ EL & $1.01 \pm 0.15$ & $1.35 \pm 0.08$ & $1.25 \pm 0.20$ \\
\hline PEG 400 & $0.95 \pm 0.10$ & $1.23 \pm 0.06$ & $1.18 \pm 0.08$ \\
\hline LSMEF & $1.02 \pm 0.05$ & $1.36 \pm 0.05$ & $1.22 \pm 0.11$ \\
\hline
\end{tabular}

The data are presented as mean $\pm \mathrm{SD}, \mathrm{n}=3$. LSMEF, liquid self-microemulsifying formulation. 
Table 4. Flowability of the solidified-LSMEF powder.

\begin{tabular}{|c|c|c|c|c|}
\hline Solid carrier & Bulk density (g/L) & Tapped density $(\mathrm{g} / \mathrm{L})$ & $\begin{array}{c}\text { Compressibility } \\
\text { index }\end{array}$ & Hausner's ratio \\
\hline Aerosil $^{\circledR} 200$ & $54.55 \pm 0.68$ & $58.61 \pm 1.04$ & $6.91 \pm 0.68$ & $1.07 \pm 0.01$ \\
\hline $\begin{array}{c}\text { Aeroperl } \\
\text { 300 Pharma }\end{array}$ & $225.59 \pm 2.92$ & $243.51 \pm 0.68$ & $7.36 \pm 1.35$ & $1.08 \pm 0.02$ \\
\hline Neusilin $^{\circledR}$ UFL2 & $111.95 \pm 1.46$ & $121.08 \pm 4.43$ & $7.47 \pm 2.63$ & $1.08 \pm 0.03$ \\
\hline
\end{tabular}

The data are presented as mean $\pm \mathrm{SD}, \mathrm{n}=3$. LSMEF, liquid self-microemulsifying formulation.

Table 5. Physical characterization of the SSMETs.

\begin{tabular}{|c|c|c|c|}
\hline Formulation & Thickness $(\mathrm{mm})$ & Hardness $(\mathrm{kp})$ & Disintegration time (min) \\
\hline F2 & $3.93 \pm 0.03$ & $1.34 \pm 0.34$ & $>30$ \\
\hline F3 & $3.88 \pm 0.03$ & $3.37 \pm 0.39$ & $>30$ \\
\hline F4 & $3.95 \pm 0.02$ & $5.09 \pm 0.52$ & $>30$ \\
\hline F5 & $4.24 \pm 0.05$ & $6.23 \pm 1.12$ & $>30$ \\
\hline F6 & $4.19 \pm 0.01$ & $5.97 \pm 0.20$ & $28.8 \pm 1.31$ \\
\hline F7 & $4.23 \pm 0.03$ & $5.84 \pm 0.92$ & \\
\hline
\end{tabular}

The data are presented as mean $\pm \mathrm{SD}, \mathrm{n}=3$. SSMET, solid self-microemulsifying tablet.

with the ratio of the surfactant/co-surfactant mixtures within $30-60 \%$.

\section{Preparation of LSMEF}

Finally, we chose the optimal LSMEF composed of Capryol ${ }^{\mathrm{TM}}$ 90, Cremophor ${ }^{\circledR} \mathrm{EL}$, and PEG 400 at $1: 1.5: 1.5$ ratio, containing $30 \mathrm{mg} / \mathrm{mL}$ of nimodipine. The LSMEF was observed to be homogenous and transparent.

\section{The binding capacity of the adsorbents for the solvents}

We employed the adsorbents as a carrier for solidification. The solvent binding capacity of the three different adsorbents was tested as shown in Table 3. The solvent binding capacity of Aeroperl ${ }^{\circledR}$ 300 Pharma was found to be the highest, followed by Neusilin ${ }^{\circledR}$ UFL2 and Aerosil ${ }^{\circledR} 200$. In addition, no statistically significant difference in binding capacity was observed between the components of the LSMEF.

\section{Evaluation of physical properties of the solidified-LSMEFs and SSMETs}

The selected LSMEF containing Capryol $^{\mathrm{TM}}$ 90, Cremophor ${ }^{\circledR}$ EL, and PEG 400 with 1 : 1.5 : 1.5 ratio was solidified with three different adsorbents such as Aerosil $^{\circledR}$ 200, Aeroperl $^{\circledR} 300$ Pharma, and Neusilin ${ }^{\circledR}$ UFL2. The flowability was evaluated for these solidified LSMEF powders, as shown in Table 4. For all the solidified LSMEF powders, the compressibility index was below $10 \%$ and Hausner's ratio was below 1.11 , meaning that all the formulations showed excellent flowability according to powder flow criteria of USP (27). Next, the solidified LSMEF powders were compressed directly to the tablets. The size of tablets was about $13 \mathrm{~mm}$ in width and $4 \mathrm{~mm}$ in thickness, and the weight of the tablets ranged from $740 \mathrm{mg}$ to $790 \mathrm{mg}$. Table 5 shows the physical properties of the tablets fabricated. F2 and F3 showed relatively low hardness under $4 \mathrm{kp}$, while the formulations solidified by Neusilin ${ }^{\circledR}$ UFL2 (F4-F7) displayed hardness over $5 \mathrm{kp}$. In addition, the disintegration time of the tablets was measured. F6 showed a short disintegration time of 14.9 min compared to other tablet formulations which were near (F7) or over 30 min (F2-F5).

\section{In vitro dissolution test}

In vitro dissolution test was performed to compare the dissolution rate of nimodipine from the SSMETs. In Figure 2, from the dissolution profiles of F1-F4, it appears that the SSMETs (F2-4) exhibited a slower dissolution rate than the LSMEF (F1). Among the F2-F4, F4 (i.e., containing Neusilin ${ }^{\circledR}$ UFL2) showed a faster dissolution rate than F2 (i.e., containing Aerosil ${ }^{\circledR}$ 200) and F3 (i.e., containing Aeroperl $^{\circledR} 300$ Pharma), but all of them could not achieve complete dissolution within 4 hours.

To further facilitate disintegration and dissolution rate, several different disintegrants, such as Amberlite ${ }^{\circledR}$ IRP-88, Primellose ${ }^{\circledR}$, and 


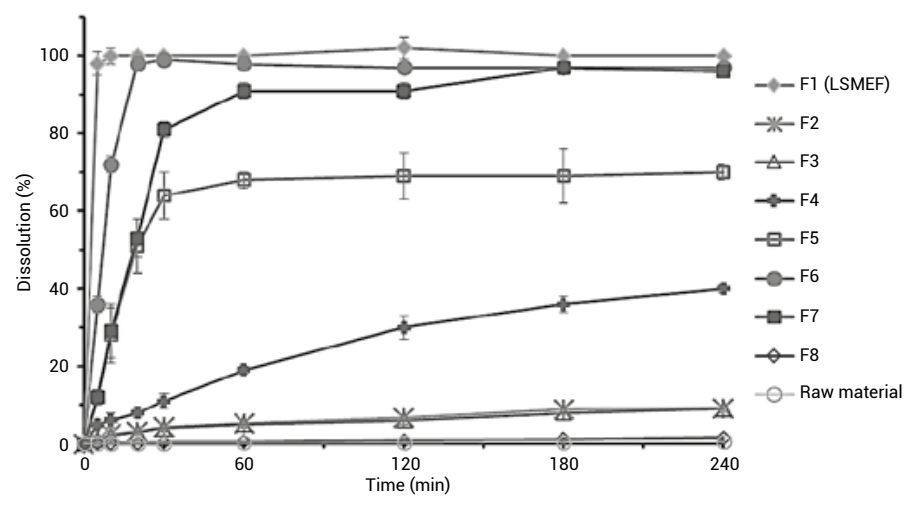

Figure 2. Dissolution profiles of liquid self-microemulsifying formulation (F1), solid self-microemulsifying tablets (F2-F7), control tablet (F8) containing nimodipine raw material and excipients used in F6, and raw material (nimodipine powder).

Polyplasdone ${ }^{\mathrm{TM}}$ were screened to finally optimize the SSMET formulation. Of these, F6 showed the highest dissolution, indicating that Primellose ${ }^{\circledR}$ could promote disintegration of the SSMETs and dissolution of the drug better than other disintegrants (Amberlite ${ }^{\circledR}$ IRP-88 and Polyplasdone ${ }^{\mathrm{TM}}$ ). Moreover, the dissolution profile of F6 was far higher than that of the control tablet (F8).

\section{Measurement of emulsion droplet sizes}

The formation of the microemulsion droplet was then confirmed by the evaluation of the droplet size when the SSMETs were diluted in SIF. The mean droplet size of the LSMEF dispersed in SIF was $71.28 \pm 1.23 \mathrm{~nm}$. The mean droplet sizes formed with the SSMETs were measured to be similar to or slightly larger than that measured with the LSMEF. This result could confirm that the microemulsion of nimodipine was successfully formed in SIF.

\section{DISCUSSION}

This study was initiated to prove the concept of solid type new dosage form of LSMEFs by developing tablets with LSMEFs, demonstrating dissolution behaviors as fast as LSMEFs. The reason for using the self-microemulsifying system was because the oil-based self-microemulsifying system was considered to be advantageous for increasing apparent solubility of highly lipophilic drugs, such as nimodipine (28). Besides, we expected that the solidified self-microemulsifying system would be more convenient for the patients and pharmaceutical scientists to handle (25).

For this, we first screened various components composing LSMEF through the solubility test and the evaluation of emulsification capability. Regarding the screening of an oil phase composing LSMEF, as an oil phase was reported to be the main carrier of the drug among the constituents in the selfmicroemulsifying system, the solubility data were primarily considered (29). Thus, we chose Capryol ${ }^{\mathrm{TM}}$ 90 as the oil phase.

Surfactants and co-surfactants act as the stabilizer of the microemulsion by preventing the coalescence of the oil droplets, which occurred at thermodynamically unstable interfaces between the oil phase and water phase (30). As our SSMETs were designed to be disintegrated and dispersed with self-microemulsifying oil droplets in the water phase, we mainly considered the emulsification capability as the selection criteria for the surfactant and the co-surfactant. In this regard, various combinations were screened, and Capryol ${ }^{\mathrm{TM}}$ 90, Cremophor ${ }^{\circledR}$ EL, and PEG 400 were selected as the optimal components of the LSMEF. Subsequently, the pseudo-ternary phase diagram was constructed, and according to the size of the microemulsion region on the diagram, we established the optimal ratio of Capryol ${ }^{\mathrm{TM}}$ 90, Cremophor ${ }^{\circledR} \mathrm{EL}$, and PEG 400 to be $1: 1.5: 1.5$. The reason for this selection was probably because this combination resulted in the most thermodynamically stable microemulsion when dispersed in water. This optimized LSMEF could be spontaneously and rapidly dispersed in SIF as micro-sized droplets.

This LSMEF $(1 \mathrm{~mL})$ could solubilize $30 \mathrm{mg}$ of nimodipine, which was considerably greater than that shown by Capryol ${ }^{\mathrm{TM}} 90$. The solubility of nimodipine in the self-microemulsifying composition was significantly increased by PEG 400 used as a cosurfactant. This result can be attributed to the fact that PEG 400 increased the solubility of nimodipine better than those measured with other excipients involved in the formulation of a self-microemulsifying system, considering the solubilizing capacity of nimodipine as well as the faster formation of microemulsions upon contact with water. 
However, liquid formulations generally have disadvantages including difficulty in handling and low patient compliance. Therefore, we attempted to solidify the LSMEF and subsequently formulate the solidified-LSMEF to the tablet formulation. To solidify the LSMEF, a higher binding capacity of adsorbents to the components was considered to be more advantageous for the efficient solidification process of the LSMEF. Among the adsorbents used, Aerosil ${ }^{\circledR} 200$ showed a slightly lower binding capacity than Neusilin ${ }^{\circledR}$ UFL2 and Aeroperl ${ }^{\circledR}$ 300 Pharma. The reason for this was the smaller specific surface area of Aerosil ${ }^{\circledR} 200$ than those of Neusilin ${ }^{\circledR}$ UFL2 and Aeroperl ${ }^{\circledR} 300$ Pharma (31, 32). In addition, the similar binding capacity of adsorbents among each component of the LSMEF is of importance because the ratio among each component included in LSMEF is crucial for forming microdroplets when dispersed in an aqueous solution (33). All the adsorbents we tested indicated a good binding capacity for the LSMEF and similar amounts of the binding capacity of each component, implying that the LSMEF would maintain their characteristic ratio between the components during the adsorption process. Therefore, we utilized all the candidate adsorbents when solidifying the LSMEF.

Before the solidified-LSMEF powders were compacted into the tablet form, the flowability of the powder was measured because it was an important factor when the tablets were molded by direct compression (34). All the solidified-LSMEF powders showed excellent flowability, so they were proper to be compressed to the tablet form. The physical tablet properties for F2-F4 were then evaluated. Regarding the tablet hardness, F2 and F3 showed the tablet hardness under $4 \mathrm{kp}$, which was lower than the normal tablet hardness of $4 \mathrm{kp}$ according to the general criteria (35), meaning that they can be too easily broken during storage. On the other hand, the formulations solidified by Neusilin ${ }^{\circledR}$ UFL2 had a hardness over $5 \mathrm{kp}$. In addition, the disintegration time of the tablet formulations (F2-F4) was measured. Although the disintegration time of the tablets (F2-F4) was not in the acceptable range, we subsequently conducted the dissolution test of F2F4 to select the adsorbent with a small effect of inhibiting the dissolution of nimodipine.

The results of in vitro dissolution test suggested that the SSMET solidified by using Neusilin ${ }^{\circledR}$ UFL (F4) showed higher dissolution profiles than those solidified by using other adsorbents (F2, F3). The reason for the low dissolution of nimodipine from F2 and F3 was because strong interactions were possibly formed between these adsorbents and nimodipine $(36,37)$. Therefore, we selected Neusilin ${ }^{\circledR}$ UFL2 as an adsorbent to solidify the LSMEF and consequently fabricate the SSMETs.

To facilitate the disintegration and dissolution of the SSMETs, we screened several disintegrants, including Amberlite ${ }^{\circledR}$ IRP-88, Primellose ${ }^{\circledR}$, and Polyplasdone ${ }^{\mathrm{TM}}$. As these are all hydrophilic materials, they could promote the aqueous medium to penetrate the tablet matrix, resulting in a breakdown of the tablet $(38,39)$. Among them, Primellose ${ }^{\circledR}$ showed a higher disintegration effect to the SSMET than Amberlite ${ }^{\circledR}$ IRP-88 and Polyplasdone ${ }^{\mathrm{TM}}$. This might be because Primellose ${ }^{\circledR}$ has relatively high swelling properties compared to Amberlite ${ }^{\circledR}$ IRP88 and Polyplasdone ${ }^{\mathrm{TM}}$. This highly swellable properties of Primellose ${ }^{\circledR}$ may enable the SSMET structure to collapse rapidly in aqueous conditions. In addition, the SSMET containing Primellose ${ }^{\circledR}$ (F6) displayed favorable tablet hardness near $6 \mathrm{kp}$, indicating that it could withstand some impacts during the storage condition.

Among F5-7, the F6 showed considerably increased apparent solubility of nimodipine, and the dissolution was complete approximately within $20 \mathrm{~min}$. Considering the disintegration time of F6 (14.9 $\mathrm{min}$ ) and complete dissolution time of about 20 min, we could infer that the LSMEF adsorbed in the Neusilin ${ }^{\circledR}$ UFL were able to be detached from the Neusilin ${ }^{\circledR}$ UFL and dispersed as micro-sized oil droplets very quickly when they contacted the SIF. In addition, the SSMET (F6) showed the formation of microdroplets (70-90 nm) successfully when dispersed in the SIF after $4 \mathrm{~h}$, which was a similar size to that of microdroplets from the LSMEF. These results demonstrated that the SSMET (F6) showed inherent advantages of LSMEF which could be spontaneously and rapidly dispersed in the GI tract as microdroplets. Consequently, the F6 was considered to be the most suitable SSMET formulation.

\section{CONCLUSION}

In this paper, we designed the SSMET composition that can significantly increase the dissolution of poorly soluble drugs, such as nimodipine. For this aim, we first optimized the LSMEF through the solubility test, the evaluation of emulsification capability, and the construction of the pseudo-ternary phase diagram. The LSMEF containing Capryol $^{\text {TM }}$ 90, Cremophor ${ }^{\circledR}$ EL, and PEG 400 with $1: 1.5: 1.5$ ratios formed stable and clear microemulsion when dispersed in an aqueous solution, and it showed a considerable increase in dissolution 
rate compared to the raw material. However, as it was still in liquid form, there were several inconveniences such as low patient compliance and difficulty in handling. To improve these problems, we tried to solidify this LSMEF with several adsorbents, and therefore Neusilin ${ }^{\circledR}$ UFL2 was chosen as the adsorbent because it showed the highest dissolution profile among the SSMETs solidified by using other adsorbents. However, the dissolution rates were still slower than those of LSMEF. Therefore, to further enhance the dissolution rate of nimodipine, we added the disintegrants to facilitate the drug release from the formulations. As a result, the final SSMET showed a dissolution rate as high as the LSMEF. Moreover, when the final SSMET was dispersed in the SIF, it was quickly disintegrated, and micro-sized oil droplets were spontaneously formed. Comprehensively, the SSMET formulation we designed, composed of Capryol ${ }^{\mathrm{TM}} 90$ as an oil phase, Cremophor ${ }^{\circledR}$ EL as a surfactant, PEG 400 as a co-surfactant, Neusilin ${ }^{\circledR}$ as an adsorbent, and Primellose ${ }^{\circledR}$ as a disintegrant could greatly enhance the dissolution of nimodipine with presenting advantages of tablet form (e.g., easy to handle and high patient compliance). Thus, it may be a promising option for formulating poorly soluble drugs, such as nimodipine.

\section{Acknowledgments}

This research was supported by the Chung-Ang University Young Scientist Scholarship in 2019 (M. T. P. S., Y. Y. T.). This work was also supported by the National Research Foundation of Korea (NRF) grant funded by the Korean government (MSIP) (No. 2015R1A5A1008958).

\section{Conflict of interest}

The authors declare no conflicts of interest.

\section{REFERENCES}

1. Kalepu S., Nekkanti V.: Acta Pharm. Sin. B. 5, 442 (2015).

2. Xia D., Cui F., Piao H., Cun D., Piao H., et al.: Pharm. Res. 27, 1965 (2010).

3. Gorajana A., Rajendran A., Rao N.: Asian J. Pharm. Res. Health Care. 2, 163 (2010).

4. AlSheyyab R., Obaidat R., Altall Y., Abuhuwaij R., Ghanma R., et al.: J. Appl. Pharm. Sci. 9, 30 (2019).

5. Ghareeb M., Neamah F.: Int. J. Pharm. Sci. Res. 8, 591 (2017).
6. Li J., Fu Q., Liu X., Li M., Wang Y.: Arch. Pharm. Res. 39, 202 (2016).

7. Riekes M.K., Kuminek G., Rauber G.S., Campos C.E.M., Bortoluzzi A.J., et al.: Carbohydr. Polym. 99, 474 (2014).

8. Semcheddine F., Guissi Nel I., Liu X., Wu Z., Wang B.: AAPS PharmSciTech. 16, 704 (2015).

9. Teng Z., Yu M., Ding Y., Zhang H., Shen Y., et al.: Int. J. Nanomedicine. 14, 119 (2019).

10. Yi T., Zhang J.: Pharmaceutics. 11, 267 (2019).

11. Dokania S., Joshi A.K.: Drug Deliv. 22, 675 (2015).

12. Yan B., Ma Y., Guo J., Wang Y.: J. Nanopart. Res. 22, 18 (2020).

13. Porter C.J., Trevaskis N.L., Charman W.N.: Nat. Rev. Drug Discov. 6, 231 (2007).

14. Chalikwar S., Belgamwar V., Talele V., Surana S., Patil M.: Colloids Surf. B Biointerfaces. 97, 109 (2012).

15. Vishnu Y.V., Kishan V., Rao Y.M.: Br. J. Pharm. Res. 3, 1015 (2013).

16. Alayoubi A., Aqueel M.S., Cruz C.N., Ashraf M., Zidan A.S.: Int. J. Pharm. 553, 441 (2018).

17. Patel A., Shelat P., Lalwani A.: Drug Deliv. Transl. Res. 4, 171 (2014).

18. Sun C., Gui Y., Hu R., Chen J., Wang B., et al.: AAPS PharmSciTech. 19, 2301 (2018).

19. Liu F., Ranmal S., Batchelor H.K., Orlu-Gul M., Ernest T.B., et al.: Drugs 74, 1871 (2014).

20. Sermkaew N., Ketjinda W., Boonme P., Phadoongsombut N., Wiwattanapatapee R.: Eur. J. Pharm. Sci. 50, 459 (2013).

21. Cerpnjak K., Zvonar A., Vrecer F., Gasperlin M.: Drug Dev. Ind. Pharm. 41, 1548 (2015).

22. Nekkanti V., Karatgi P., Prabhu R., Pillai R.: AAPS PharmSciTech. 11, 9 (2010).

23. Seo Y.G., Kim D.H., Ramasamy T., Kim J.H., Marasini N., et al.: Int. J. Pharm. 452, 412 (2013).

24. Shanmugam S., Baskaran R., Balakrishnan P., Thapa P., Yong C.S., et al.: Eur. J. Pharm. Biopharm. 79, 250 (2011).

25. Silva L.A.D., Almeida S.L., Alonso E.C.P., Rocha P.B.R., Martins F.T., et al.: Int. J. Pharm. 541, 1 (2018).

26. Kale S.N., Deore S.L.: Sys. Rev. Pharm. 8, 39 (2016).

27. United States Pharmacopeia and National Formulary (USP 35/NF 30), USA 2012.

28. Park H., Ha E.S., Kim M.S.: Pharmaceutics. 12, 365 (2020).

29. Gurram A.K., Deshpande P.B., Kar S.S., Nayak U.Y., Udupa N., et al.: Indian J. Pharm. Sci. 77, 249 (2015). 
30. Kim D.S., Cho J.H., Park J.H., Kim J.S., Song E.S., et al.: Int. J. Nanomedicine. 14, 4949 (2019).

31. Khanfar M., Al-Nimry S.: AAPS PharmSciTech. 18, 2358 (2017).

32. Abdelmonem R., Azer M.S., Makky A., Zaghloul A., El-Nabarawi M., et al.: Drug Des. Devel. Ther. 14, 4343 (2020).

33. Rahman M.A., Hussain A., Hussain M.S., Mirza M.A., Iqbal Z.: Drug Dev. Ind. Pharm. 39, 1 (2013).

34. Khlibsuwan R., Pongjanyakul T.: Int. J. Pharm. 535, 410 (2018).
35. Prashanthievangelin M., Kumar P.P., Zakeer S., Chandrasekhar G.S., Pravallika B., et al.: The Pharma Innov. J. 9, 93 (2020).

36. Beg S., Swain S., Singh H.P., Patra Ch N., Rao M.E.: AAPS PharmSciTech. 13, 1416 (2012).

37. Milovic M., Djuris J., Djekic L., Vasiljevic D., Ibric S.: Int. J. Pharm. 436, 58 (2012).

38. Desai P.M., Liew C.V., Heng P.W.S.: J. Pharm. Sci. 105, 2545 (2016).

39. Rojas J., Guisao S., Ruge V.: AAPS PharmSciTech. 13, 1054 (2012).

(C) 2021 by Polish Pharmaceutical Society. This is an open-access article under the CC BY NC license (http://creativecommons.org/licenses/BY/4.0/). 